\title{
A complexidade da formação do professor de matemática e suas implicações para a prática docente
}

\author{
Leila Cunha de Albuquerque* \\ Cleyton Hércules Gontijo**
}

\section{Resumo}

Considerando que a formação inicial e a formação continuada configuram-se como elementos de grande importância para o desenvolvimento e desempenho profissional do docente ao longo de sua trajetória, este artigo discutirá alguns aspectos que permeiam a formação do professor de matemática, trazendo informações acerca das pesquisas desenvolvidas nessa área e a perspectiva de formação docente defendida entre os educadores matemáticos nos últimos anos. Essa abordagem tem como principais objetivos fomentar a discussão sobre a formação docente e promover um movimento de reflexão nesse sentido, tendo em vista que, por meio do processo de formação inicial e continuada, o professor constrói e reconstrói conhecimentos que, articulados com sua prática cotidiana, gerará saberes que o nortearão em sua tarefa primordial, o ensinar, para que seja desenvolvida de forma adequada e significativa.

Palavras-chave: Formação continuada. Formação docente. Professor de matemática.

\section{Introdução}

Nos últimos vinte anos, os pesquisadores em educação matemática têm voltado suas atenções para a formação dos professores que ensinam matemática. Um exemplo é a constituição de um Grupo de Trabalho da Sociedade Brasileira de Educação Matemática (Sbem), o qual congrega pesquisadores de programas de pós-graduação em educação e em educação matemática, entre outros membros, dedicados a investigar a formação e o desenvolvimento profissional do professor que ensina matemática em todos os níveis de ensino.

Professora de matemática da Secretaria de Estado de Educação do Distrito Federal e Mestra em Educação pela Universidade de Brasília (UnB). E-mail: leila191076@gmail.com

* Professor do Programa de Pós-Graduação em Educação da UnB. E-mail: cleyton@unb.br 
Todavia, a produção acadêmica apresentada nos principais eventos promovidos pela Sbem - a saber, o Seminário Internacional de Pesquisas em Educação Matemática (Sipem) e o Encontro Nacional de Educação Matemática (Enem) tem demonstrado que ainda há uma dispersão em relação às principais questões que tratam do tema formação docente, ou seja, há "uma grande predominância de questões que de certa forma tangenciam a formação docente, mas não compõe [sic] pesquisas propriamente ditas sobre formação de professores" (NACARATO; PAIVA, 2008, p. 12). Ressalta-se, entretanto, que a própria Sbem vem denunciando problemas relativos à formação de professores de matemática. Dentre esses problemas, destacam-se:

A não incorporação, nos cursos, das discussões e dos dados de pesquisa da área da Educação Matemática; uma Prática de Ensino e um Estágio Supervisionado, oferecidos geralmente na parte final dos cursos, realizados mediante práticas burocratizadas e pouco reflexivas que dissociam teoria e prática, trazendo pouca eficácia para a formação profissional dos alunos.

O isolamento entre escolas de formação e o distanciamento entre as instituições de formação de professores e os sistemas de ensino da educação básica.

A desarticulação quase que total entre os conhecimentos matemáticos e os conhecimentos pedagógicos e entre teoria e prática (SBEM , 2003, p. 5-6).

Esses aspectos têm se constituído em fontes de investigação, e, somando-se a tal repertório, a discussão e o estudo de temas como os saberes docentes, trabalho colaborativo, projetos e programas de formação docente começaram a ganhar destaque, caracterizando de forma mais sistemática a pesquisa nessa área.

Pesquisar temas como os citados faz-se necessário, pois a área em que se inserem é um dos campos da educação básica no qual há uma grande carência de professores. Além disso, os estudantes brasileiros apresentam nos exames nacionais e internacionais baixo desempenho. Acerca da carência de professores, dados do Ministério da Educação (MEC) e do Instituto Nacional de Estudos e Pesquisas Educacionais Anísio Teixeira (Inep), apresentados pela Folha de São Paulo em 19/09/2009, mostram que, de 134 mil professores de matemática formados nos últimos anos, apenas 43 mil estavam em sala de aula (apud LIBÂNEO, 2011, p. 82).

Segundo Manrique (2009), em 2005, havia no Brasil 457 cursos de matemática que realizaram o Exame Nacional de Desempenho de Estudantes (Enade). A autora, também, verificou que, em 2006, segundo a Sinopse do Ensino Superior do Inep, existiam 567 cursos de graduação presenciais para a formação de professores de matemática, apontando um aumento de quase $25 \%$. Embora esse crescimento seja bastante significativo, ainda não foi suficiente para resolver problemas relacionados à falta de professores nos sistemas públicos de ensino. 
A insuficiência de professores com habilitação em ciências e matemática constitui um dos principais gargalos do ensino ofertado pelas redes públicas. Uma das implicações negativas desse fato consiste na precária formação lograda por parcela significativa do aluno, que, em última instância, comprometerá a empregabilidade e/ou produtividade do trabalho (CORBUCCI, 2011, p. 579).

Mais que aumentar a oferta de vagas em cursos de licenciatura, torna-se necessário garantir que os seus egressos venham a atuar, de fato, no magistério público. Para tanto, será imprescindível uma política de valorização do magistério mais abrangente, que compreenda, pelo menos, a criação e a implementação de planos de carreiras, assim como a melhoria das condições de trabalho. Desse modo, seria possível não apenas aumentar, quantitativa e qualitativamente, os quadros docentes da educação básica, como também, e principalmente, evitar a evasão dos mais qualificados, que, via de regra, dispõem de outras oportunidades de inserção no mercado de trabalho (CORBUCCI, 2011).

Pelo pouco que se expôs até aqui, já é possível perceber que discutir a formação de professores corresponde a uma tarefa bastante complexa, não sendo possível em poucas páginas abordar todos os elementos que a constituem ou a tangenciam. Nesse sentido, tomar-se-á como propósito discutir a formação do professor de matemática como instrumento de profissionalização docente, considerando esse caminho como um dos mais viáveis para resolver os problemas que circundam essa temática. Tal discussão será orientada por alguns dados estatísticos (GATTI; NUNES, 2009), buscando problematizá-los na análise de elementos essenciais à formação do licenciado em matemática.

\section{A formação do professor de matemática}

Muitos estudiosos (NÓVOA, 1999; TARDIF; LESSARD; GAUTHIER, 2001; FIORENTINI; NACARATO, 2005; ROLDÃO, 2007) têm se debruçado na tarefa de desvelar e estudar os constituintes de uma formação que contribua para o desenvolvimento docente de forma a fazer que este adquira competências e habilidades capazes de incidir efetiva e construtivamente na sua ação de ensinar.

Considera-se que a formação, inicial ou continuada, exerce grande influência na percepção, construção e organização de diversos saberes docentes, que, de forma conjunta, se manifestarão no ato de ensinar, ou seja, no fazer docente em seu cotidiano. A formação docente não é a única responsável pela construção do saber profissional, mas se apresenta como constituinte indispensável, uma vez que o conhecimento profissional não poderia se sistematizar, consistentemente, na ausência de processos de formação. 
Baseando-se nas abordagens apresentadas por Roldão (2007), Nóvoa (1999), Tardif, Lessard e Gauthier (2001), dentre outros, é possível perceber uma perspectiva de formação docente que prima pela articulação entre os saberes científicos, os saberes específicos de cada área de atuação docente (saberes de conteúdo, curriculares, didático-pedagógicos) e os saberes experienciais que são adquiridos no cotidiano do professor. A formação inicial e/ou continuada deve promover a construção dos saberes docentes de maneira que estes relacionem os já validados cientificamente aos que estão em processo de construção por parte do professor, articulando o conhecimento adquirido na formação com a sua experiência de vida e profissional.

Proporcionar uma formação que ofereça condições de apropriação de elementos que constituirão o saber docente é necessário para que, além de dominar o conhecimento matemático, por meio da construção desse conhecimento específico, o professor consiga transformá-lo em conhecimento matemático escolar. Portanto, as "pesquisas vêm evidenciando a necessidade de que, em programas de formação, os conteúdos matemáticos sejam visitados e revisitados, mas é necessário pensar sob que olhar isso deveria acontecer" (NACARATO; PAIVA, 2008, p. 14).

Um dos enfoques presente na discussão acerca da formação do professor de matemática é a inserção, no currículo de formação, de disciplinas do campo da educação matemática, pois este se caracteriza como "uma práxis que envolve o domínio do conteúdo específico (a matemática) e o domínio de ideias e processos pedagógicos relativos à transmissão/assimilação e/ou à apropriação/construção do saber matemático escolar" (FIORENTINI; LORENZATO, 2006, p. 5). Essa inserção é reflexo da percepção e preocupação com o fato de que, para ensinar matemática, não é suficiente apenas dominar o "saber conteudinal curricular" (ROLDÃO, 2007), sendo preciso, também, construir um saber pedagógico articulado com o saber relativo ao conteúdo de ensino pelo professor em processo de formação. Fomentar essa discussão tem sido um dos grandes desafios de pesquisadores e especialistas ao longo das últimas décadas.

Apesar dos esforços dos pesquisadores de educação matemática, muitos cursos de licenciatura dessa área ainda deixam de contemplar no currículo uma articulação entre saberes técnico-científicos e saberes pedagógicos. A pesquisa coordenada por Gatti e Nunes (2009) revela que a distribuição dos conteúdos da formação do professor de matemática não se dá de forma semelhante entre os diversos cursos que existem no país, indicando que cada currículo privilegia alguns campos em detrimentos de outros. Segundo as autoras, podem-se identificar três tipos de cursos de licenciatura em matemática: 
$1^{\circ}$ os que investem em disciplinas de formação específica em Matemática, contemplando conteúdos discriminados nas Diretrizes Curriculares para Cursos de Matemática apenas para cursos de Bacharelado. São cursos que estudam de maneira bem aprofundada os conteúdos de Álgebra, Análise (incluem disciplinas intituladas por Equações Diferenciais, Variáveis Complexas, Cálculo Vetorial e Topologia) e Geometria - abordando Geometria das Transformações e as não euclidianas. As disciplinas pedagógicas nesses cursos são poucas, bem como as respectivas cargas horárias; $2^{\circ}$ os que investem em uma formação básica de Matemática, procurando atender as Diretrizes Curriculares para Cursos de Matemática, e uma formação pedagógica, atribuída para a área da Educação, mas, alocando um espaço pequeno para disciplinas da área da Educação Matemática; $3^{\circ}$ os que oferecem disciplinas de formação específica em Matemática, de forma a atender as Diretrizes Curriculares para Cursos de Matemática, e disciplinas atribuídas à área de Educação Matemática, como Didática da Matemática, Filosofia da Matemática, História da Matemática e Tópicos de Educação Matemática, e algumas disciplinas para a área de Educação (GATTI; NUNES, 2009, p. 109).

A ampliação do foco do $1^{\circ}$ e do $2^{\circ}$ tipos de formação é fundamental, incluindo os conhecimentos do campo da didática da matemática, que são indispensáveis na formação do professor desse componente curricular, "uma vez que oferecem as condições básicas para que ele torne um determinado conhecimento matemático passível de ser apropriado pelo aluno" (VARIZO, 2008, p. 55). Em outras palavras, trata-se de tornar o conhecimento matemático acessível a todos, desmitificando a ideia de que a matemática é para gênios. Nesse sentido, a didática da matemática revela-se necessária ao longo de todo o processo de formação, para que o licenciando, num movimento dialético entre o conhecimento específico (matemático) e o conhecimento didático, seja capaz de produzir saberes que serão essenciais na organização e execução do trabalho pedagógico, cuja finalidade é ensinar/aprender matemática. Promover o diálogo entre o conhecimento da disciplina e o conhecimento didático significa possibilitar o desenvolvimento dos saberes didático-pedagógicos do docente, e isso ainda é um grande desafio para os cursos de licenciatura, pois, em sua maioria,

Em termos de carga horária, proporcionalmente, Didática Geral ocupa 1,6\% do tempo dessa licenciatura, conhecimentos dirigidos à escola básica, 18,5\%, conhecimentos aprofundados específicos da área disciplinar, $34,1 \%$. Interessante é notar que Pesquisa e TCC ocupam 3,7\% do tempo do curso, menos horas do que Atividades complementares (5\%), que contemplam rótulos como "Atividades acadêmico-científico-culturais", "Atividades complementares”, "Estudos independentes” (GATTI; NUNES, 2009, p. 100).

Varizo(2008), também, chama a atenção para a importância de promover, durante o período de formação, a articulação entre as disciplinas de didática de matemática, práticas de ensino em matemática e os estágios supervisionados. Segundo a pesquisadora, "é difícil desvincular a pesquisa no campo das didáticas específicas da questão da prática de ensino e da ação do professor na sala de aula” (VARIZO, 2008, p. 49). 
No entanto, a maioria dos cursos de licenciatura trabalha, por exemplo, o estágio supervisionado de forma isolada. O licenciando vai à prática sozinho, sem o acompanhamento de um professor que o oriente de maneira eficaz, dando-lhe suporte nas situações adversas que podem se apresentar durante suas atividades nas escolas onde vivenciará a prática docente. Gatti e Nunes (2009), ao analisar os currículos dos cursos de licenciatura em matemática, detectaram que:

Nos projetos e currículos não fica claro como ocorre a integralização das horas obrigatórias de estágios nas diversas instituições. Algumas instituições não distinguem as atividades destinadas à Prática de Ensino e ao Estágio. Os processos de supervisão dos estágios e sua validação também não são objeto de tratamento explicitado (2009, p. 109).

Pode-se inferir, a partir dessas informações, que o estágio nos cursos de licenciatura em matemática não está contribuindo para o início da prática do futuro professor. Ressalta-se, entretanto, que o estágio curricular supervisionado é um momento de formação profissional caracterizado pelo exercício da profissão in loco, que tem, entre outros objetivos, oferecer ao futuro professor um conhecimento da realidade em situação de trabalho, diretamente em unidades escolares, atuando em processos de capacitação e organizando atividades de aprendizagem.

A presença do estagiário na escola visa a propiciar momentos de observação, participação e atuação plena na condução dos processos educativos em sala de aula, regendo turmas, conhecendo, assim, a dinâmica das relações estabelecidas nesse espaço, de modo a desenvolver as competências docentes para o exercício da profissão. Para tanto, devem vivenciar situações em que possam discutir os problemas do cotidiano e analisá-los à luz das teorias estudadas, a fim de elaborar estratégias de intervenção que permitam tomadas de decisões adequadas. O estágio supervisionado é o espaço em que os estudos teóricos se confrontarão com os aspectos práticos, favorecendo a relação teoria-prática que caracteriza o trabalho pedagógico.

Em relação a outros campos de conhecimento necessários à formação dos professores de matemática, a pesquisa de Gatti e Nunes assim revela:

No que se refere aos "Sistemas Educacionais", que já representam muito pouco no total de horas oferecidas (3,3\%), vale destacar que desse percentual 2,0\% corresponde à "Estrutura e funcionamento do ensino", com 0,7\% das horas dedicadas a "Currículo", 0,5\% a "Gestão escolar" e $0,1 \%$ a "Ofício docente". Apesar de disciplinas relacionadas a esses temas serem importantes na formação de professores, nota-se que os cursos de Licenciatura em Matemática ainda não incorporaram em suas matrizes curriculares um número de horas maior quanto a aspectos importantes para a formação de profissionais que vão atuar nas escolas de ensino fundamental e médio (2009, p. 100).

Acredita-se que a articulação, nos cursos de formação, entre os saberes adquiridos com as disciplinas de didática geral, didática de matemática, as que tratam 
da gestão e organização dos sistemas educacionais e as relacionadas às práticas de ensino de matemática pode estabelecer um movimento capaz de alavancar a construção dos saberes da experiência, que representam o conjunto dos saberes atualizados, apreendidos e requeridos no quadro da profissão docente (TARDIF; LESSARD; LAHAYE, 1991) e que não podem ser obtidos nas instituições de formação ou nos currículos. Porém, é admissível conceber que a formação desse futuro professor pode promover a inicialização do desenvolvimento desse saber. De acordo com Melo, "o saber da experiência é um saber articulado, que tem a ver com o conteúdo, com a pedagogia, com o ensino e com o currículo como um todo" (2005, p. 38). Fiorentini e Castro corroboram esse pensamento, quando observam que:

[...] de acordo com essa visão de formação docente, os saberes experienciais dos professores não se constituem isoladamente na prática. Emergem do diálogo que o professor estabelece entre o que presencia na prática escolar e o que sabe, estudou e aprende na interlocução com a literatura educacional e com outros sujeitos da prática educativa (2003, p. 126).

Outro aspecto recorrente nas discussões sobre formação docente, também no campo da educação matemática, diz respeito à participação ativa durante os processos de formação inicial ou continuada do professor, de forma a permitir que este possa manifestar seus pensamentos e questionamentos, fazendo-o agir na sua própria formação. Essa perspectiva encontra fundamento nas correntes que defendem que o professor deve ser ator e autor de sua formação, viabilizando a constituição de um profissional reflexivo, crítico e investigativo nesse processo. A esse respeito, Paiva menciona que:

[...] saber por que se ensina, para que se ensina, para quem e como se ensina é essencial ao fazer em sala de aula. O professor precisa estar em constante formação e processo de reflexão sobre seus objetivos e sobre a consequência de seu ensino durante sua formação, na qual ele é o protagonista, assumindo a responsabilidade por seu próprio desenvolvimento profissional (2008, p. 92).

Uma formação que oportuniza a ativa participação do docente nesse processo tende a torná-lo capaz de, num movimento contínuo e autônomo, construir novos conhecimentos e, também, de significá-los e ressignificá-los ao longo de sua trajetória profissional. Formar professores com base nessa visão rompe com o conceito de formação que se preocupa "com o que o professor não sabe, partindo de teorias e não avançando em outros aspectos", e passa a trabalhar com a perspectiva do desenvolvimento profissional, que vê "o professor com potencialidades próprias, como um profissional autônomo e responsável pela construção de seus saberes" (PAIVA, 2008 , p. 93). Uma formação comprometida com o desenvolvimento profissional, em especial do professor de matemática, tende a valorizar o docente, preocupando-se, constantemente, com sua aprendizagem e seu desenvolvimento. 
Cabe esclarecer que o conceito de formação docente não se confunde com o de desenvolvimento profissional, ainda que, em alguns momentos, ambos apresentem noções próximas. É importante saber que a formação contribui para o desenvolvimento profissional, sendo seu elemento constituinte, mas ambos não têm significados equivalentes. Pode-se afirmar que o processo de desenvolvimento profissional contém a formação inicial e continuada. "A formação é um elemento importante de desenvolvimento profissional, mas não é o único e talvez não seja o decisivo" (IMBERNÓN, 2010, p. 46).

Ferreira (2008), assim como outros pesquisadores, também defende que o professor de matemática se desenvolve profissionalmente, ao longo de sua trajetória docente, por meio de suas experiências com o ensino e a aprendizagem, sem espaço pré-definido ou tempo específico. Todavia, considera que esse processo de desenvolvimento sofre influência de "fatores pessoais, motivacionais, sociais, cognitivos e afetivos - envolve a formação inicial e a continuada, bem como a história pessoal como aluno e professor" (FERREIRA, 2008, p. 149).

A fim de favorecer que o futuro professor seja mais ativo em sua formação, alguns pesquisadores (PIMENTA; GARRIDO; MOURA, 2001; NACARATO, 2005; FIORENTINI, 2004) apontam a pesquisa como um espaço promissor nos processos de formação. Essa é uma linha de investigação ainda nova nessa área, mas que tem o intuito de investigar e analisar a influência da pesquisa como espaço de formação docente, além de apontar de que maneira isso se faz possível. Busca-se, contudo, desenvolver um trabalho de pesquisa junto ao professor, e não apenas do e sobre o professor. É a participação do professor como pesquisador e agente de sua própria formação.

Um dos espaços privilegiados para o envolvimento do futuro professor em atividades de pesquisa, experimentando todas as etapas do processo investigativo, refere-se à oportunidade de elaborar, de forma autônoma, ainda que sob a orientação de um professor experiente, um trabalho de final de curso. Entretanto, segundo Gatti e Nunes,

[...] nem todas as instituições apresentam disciplinas relacionadas à "Pesquisa e TCC", o que é preocupante, considerando que atualmente a elaboração de um Trabalho de Conclusão de Curso é item obrigatório para a obtenção do diploma de licenciado em Matemática (2009, p. 101).

Para além dos espaços de formação inicial e das investigações que sugerem o desenvolvimento de pesquisas como instrumentos de formação docente, destaca-se a importância dos trabalhos colaborativos como propulsores de desenvolvimento profissional. Essa perspectiva, também, tem destaque nas pesquisas que tratam da formação continuada do professor de matemática. Conforme Lopes (2005), gru- 
pos colaborativos apresentam contribuições e potencialidades que apontam uma perspectiva significativa para os processos de formação continuada de professores, promovendo seu desenvolvimento profissional. Em suas palavras,

Os projetos colaborativos adquirem importante dimensão quando consideram o processo reflexivo na e sobre a prática docente, o conhecimento e desenvolvimento profissional do professor, não se limitando apenas às questões conceituais de uma área do conhecimento (LOPES, 2005, p. 124).

Nos trabalhos coletivos e colaborativos - que têm se apresentado como fonte de aprendizagem para pesquisadores e professores pesquisadores -, "o grupo torna-se o contexto no qual são criadas oportunidades para o professor explorar e questionar seus próprios saberes e práticas, bem como para conhecer saberes e práticas de outros professores" (FERREIRA, 2008, p. 152). Dentre os trabalhos colaborativos mais citados, estão a pesquisa-ação, a pesquisa cooperativa e a pesquisa colaborativa.

Ao tratar da formação do professor de matemática, não se pode deixar de discutir a importância de promover estudos voltados à formação do professor polivalente, isto é, daquele que atua na educação infantil e nos anos iniciais do ensino fundamental. Esses professores são responsáveis por orientar e proporcionar o desenvolvimento da construção dos primeiros conceitos matemáticos na criança, e isso leva a que a preocupação com a formação inicial de professores que trabalham com alunos dos anos iniciais do ensino fundamental seja potencializada. Curi (2008), com base em levantamentos e análises realizadas nos fluxos curriculares e nas ementas das disciplinas que envolvem matemática nos cursos de pedagogia, constatou que apenas 36 a 72 horas do curso, aproximadamente, são destinadas ao desenvolvimento de disciplinas abordando essa área de conhecimento, ou seja, $4 \%$ a $5 \%$ da carga horária total do curso. A pesquisadora evidencia não ter encontrado, em qualquer dos cursos por ela investigados, "indicações bibliográficas de pesquisas na área de educação matemática, em particular sobre o ensino e aprendizagem de matemática nas séries iniciais do Ensino Fundamental" (CURI, 2008, p. 68). Os estudos de Curi (2008) mostram, ainda, que a produção de livros, de materiais didáticos e as pesquisas voltadas para a formação matemática dos professores polivalentes são bastante restritas.

Os dados apresentados por Curi (2008) indicam que o tempo destinado ao trabalho com a matemática nos cursos de pedagogia é insuficiente para que os seus egressos desenvolvam competências e habilidades para organizar o trabalho pedagógico no início do ensino fundamental. Para compensar essa limitação, os professores necessitam receber uma formação que lhes dê condições de trabalhar com essa área 
do saber de forma a contribuírem com a construção do conhecimento matemático pelo aluno desde o início do seu processo de escolarização.

\section{Considerações finais}

Discutir a formação do professor de matemática tem se mostrado um desafio para os educadores devido a sua complexidade. Não se pode, porém, perseguir um ensino de qualidade sem cuidar devidamente da formação daqueles que são de fundamental importância no processo de ensino e aprendizagem escolar. Não é possível prever que alunos aprendam bem e que escolas desempenhem seu papel com sucesso sem que os professores estejam presentes, exercendo sua função de maneira eficaz.

Estudar, discutir e compartilhar as abordagens que os especialistas citados neste trabalho trazem acerca da função e formação docente são ações que levam a estabelecer um movimento de reflexão e percepção, o qual evidencia que manifestar preocupação com a formação do professor significa dar atenção à base que sustenta o fazer docente. Por meio desses momentos, seja na formação inicial ou continuada, durante a trajetória profissional, o professor constrói e reconstrói conhecimentos que, articulados com sua prática cotidiana, produzirá saberes que lhes serão indispensáveis, conduzindo e permitindo que a ação de ensinar aconteça de forma positiva e significativa nos mais diversos cenários educacionais.

\section{The complexity of mathematics teacher education and its implications for teaching practice}

\section{Abstract}

Considering that the initial and continued education are set as elements of huge importance to teachers' development and professional perform along their path, this article discusses about some points that permeate the Math teachers'education bringing up information from researchers developed in this area and the perspective of teacher's education defended among Math educators in recent years. This text has as main aim to promote some discussion about teachers' education and promote a reflection movement toward this aspect. Considering that, through the initial process and continued education, the teacher builds and rebuilds knowledge that, articulated with everyday practice, it will create some knowledge that will guide teachers' main task: teaching, this way, this task will be done in an appropriate and significantly manner.

Keywords: Continued education. Math teacher. Teacher's education. 


\section{Referências}

CORBUCCI, P. R. Dimensões estratégicas e limites do papel da educação para o desenvolvimento brasileiro. Revista Brasileira de Educação, Campinas, v. 16, n. 48, p. 563-584, set./dez. 2011.

CURI, E. Análise de propostas presentes no material de matemática do PEC-Universitário, à luz de resultados de investigações e teorias sobre formação de professores. In: NACARATO, A. M.; PAIVA, M. A. V. (Org.). A formação do professor que ensina matemática: perspectivas e pesquisas. Belo Horizonte: Autêntica, 2008. p. 61-76.

FERREIRA, A. C. O trabalho colaborativo como ferramenta e contexto para o desenvolvimento profissional: compartilhando experiências. In: NACARATO, A. M.; PAIVA, M. A. V. (Org.). A formação do professor que ensina matemática: perspectivas e pesquisas. Belo Horizonte: Autêntica, 2008. p. 149-166.

FIORENTINI, D. Pesquisar práticas colaborativas ou pesquisar colaborativamente? In: BORBA, M. de C.; ARAÚJO, J. de L. (Org.). Pesquisa qualitativa em educação matemática. Belo Horizonte: Autêntica, 2004. p. 53-85.

; CASTRO, F. C. de. Tornando-se professor de matemática: o caso de Allan em prática de ensino e estágio supervisionado. In: FIORENTINI, D. Formação de professores de matemáti$c a$ : explorando novos caminhos com outros olhares. Campinas, SP: Mercado de Letras, 2003. p. 121-156.

; LORENZATO, S. Investigação em educação matemática: percursos teóricos e metodológicos. Campinas, SP: Autores Associados, 2006.

; NACARATO, A. M. (Org.). Cultura, formação e desenvolvimento profissional de professores que ensinam matemática. São Paulo: Musa Editora, 2005.

GATTI, B. A.; NUNES, M. M. R. (Org.). Formação de professores para o ensino fundamental: estudo de currículos das licenciaturas em pedagogia, língua portuguesa, matemática e ciências biológicas. São Paulo: FCC/DPE, 2009.

IMBERNÓN, F. Formação continuada de professores. Trad. de Juliana dos Santos Padilha. Porto Alegre: Artmed, 2010.

LIBÂNIO, J. C. Escola pública brasileira, um sonho frustrado: falharam as escolas ou as políticas educacionais? In: LIBÂNIO, J. C.; SUANNO, M. V. R. Didática e escola em uma sociedade complexa. Goiânia: CEPED, 2011. p. 75-95.

LOPES, C. A. E. Um grupo colaborativo de educadores de infância e suas relações com a estocástica. In: FIORENTINI, D.; NACARATO, A. M. (Org.). Cultura, formação e desenvolvimento profissional de professores que ensinam matemática. São Paulo: Musa Editora, 2005. p. 108-127.

MANRIQUE, A. L. Licenciatura em matemática: formação para a docência x formação específica. Educação Matemática Pesquisa, São Paulo, v. 11, n. 3, p. 515-534, 2009.

MELO, G. F. A. Saberes docentes de professores de matemática: a formação continuada em ambientes virtualizados. In: FIORENTINI, D.; NACARATO, A. M. (Org.). Cultura, formação e desenvolvimento profissional de professores que ensinam matemática. São Paulo: Musa Editora, 2005. p. 33-48.

NACARATO, A. M. A escola como lócus de formação e de aprendizagem: possibilidades e riscos da colaboração. In: FIORENTINI, D.; NACARATO, A. M. (Org.). Cultura, formação e desenvol- 
vimento profissional de professores que ensinam matemática. São Paulo: Musa Editora, 2005. p. 175-195.

; PAIVA, M. A. V. (Org.). A formação do professor que ensina matemática: perspectivas e pesquisas. Belo Horizonte: Autêntica, 2008.

NÓVOA, A. Os professores na virada do milênio: do excesso dos discursos à pobreza das práticas. Revista Educação e Pesquisa, São Paulo, v. 25, n. 1, p. 11-20, jan./jun. 1999.

PAIVA, M. A. V. O professor de matemática e sua formação: a busca da identidade profissional. In: NACARATO, A. M.; PAIVA, M. A. V. (Org.). A formação do professor que ensina matemática: perspectivas e pesquisas. Belo Horizonte: Autêntica, 2008. p. 89-112.

PIMENTA, S. G.; GARRIDO, E.; MOURA, M. O. Pesquisa colaborativa na escola facilitando o desenvolvimento profissional de professores. In: REUNIÃO ANUAL DA ANPED, 24, Caxambu, MG, 2001. Anais... Caxambu, MG: Associação Nacional de Pós-Graduação e Pesquisa em Educação, 2001. p. 1-21. Disponível em: <http://www.anped.org.br/reunioes/24/ts.htm>. Acesso em: 3 maio 2010.

RIOS, T. A. Compreender e ensinar: por uma melhor docência da melhor qualidade. São Paulo: Cortez, 2010.

ROLDÃO, M. do C. Função docente: natureza e construção do conhecimento profissional. Revista Brasileira de Educação, Rio de Janeiro, v. 12, n. 34, p. 93-103, jan./abr. 2007.

SOCIEDADE BRASILEIRA DE EDUCAÇÃO MATEMÁTICA (Sbem). Subsídios para a discussão de propostas para os cursos de licenciatura em matemática: uma contribuição da sociedade brasileira de educação matemática. São Paulo, 2003. Disponível em: <www.prg.unicamp.br/ccq/ subformacaoprofessores/SBEM_Licenciatura.pdf>. Acesso em: 15 maio 2009.

TARDIF, M.; LESSARD, C.; GAUTHIER, C. Formação dos professores e contextos sociais. Trad. de Emília Laura Seixas. Porto, Portugal: Rés, 2001.

; ___ _ LAHAYE, L. Os professores face ao saber - esboço de uma problemática do saber docente. Teoria \& Educação, Porto Alegre, n. 4, p. 215-234, 1991.

VARIZO, Z. da C. M. Os caminhos da didática e sua relação com a formação de professores de matemática. In: NACARATO, A. M.; PAIVA, M. A. V. (Org.). A formação do professor que ensina matemática: perspectivas e pesquisas. Belo Horizonte: Autêntica, 2008. p. 43-59. 